\title{
Improving Adherence to PrEP Though Real-Time Monitoring Paired with Personalized, Automated Text Interventions
}

Christian Klimas ${ }^{1}$; Clyde Moreland ${ }^{1,2}$, MD; Cynthia Sleppy ${ }^{1}$, ARNP; Rebecca Nessen ${ }^{1}$, MPH; Mark Mann ${ }^{1}$, MPH; Rachel De Jesus ${ }^{3}$, MS

\author{
${ }^{1}$ Metro Wellness and Community Centers, St Petersburg, FL, United States \\ ${ }^{2}$ St Joseph's Children's Hospital of Tampa, Tampa, FL, United States \\ ${ }^{3}$ SMRxT, Orlando, FL, United States
}

\section{Corresponding Author:}

Christian Klimas

Metro Wellness and Community Centers

3251 3rd Avenue North, Suite 125

St Petersburg, FL,

United States

Phone: 3213854

Email: ChristianK@metrotampabay.org

\begin{abstract}
Background: Pre-exposure prophylaxis, or PrEP (brand name Truvada), is a once daily medication that reduces the chance of contracting HIV by more than $90 \%$ for those facing an elevated risk of HIV exposure. When starting PrEP, it takes at least seven days to reach high levels of protection and seven consecutive days to maintain protection. Unfortunately, many do not follow the guidelines for PrEP, leaving them vulnerable. Metro Wellness and Community Centers (Metro Wellness) provides comprehensive HIV services throughout Tampa Bay. Metro Wellness, with Mail-Meds Clinical Pharmacy (Mail-Meds), deployed a new technology, Nomi, to support patients in their journey of HIV prevention. Nomi accurately captures data through a connected prescription bottle to reveal how patients take their medications in real-time. Nomi translates data into actionable information for automatic patient interventions and engagement.
\end{abstract}

Objective: To understand patients' ability to adopt innovative technology to maintain adherence to the PrEP regimen. In addition, the study will determine if technology converts non adherent days to adherent through automated, personalized interventions.

Methods: Patients enrolled in Nomi must be HIV negative, at high-risk for HIV infection, receiving PrEP for the first time through Metro Wellness, and have a cell phone with SMS capabilities. Patients receive their Truvada prescription in a connected bottle that measures the amount of medication taken by weight. The prescriptions are filled by Mail-Meds in clinic pharmacy. As patients take Truvada, the bottle sends data to Nomi. Nomi reviews the data and sends automatic text interventions and escalations based on the patient's behavior. The texts sent are designed to be discrete to ensure patient privacy. Nomi also communicates with Metro Wellness staff. Staff receive escalations from Nomi to reach out the patents needing additional assistance.

Results: The program is ongoing. All reported results are as of July 31, 2018. Forty-nine patients have been enrolled. Days on therapy range from 29 to 378 . The average length of therapy is 107 days. Reasons for ending therapy include, patients changing prescribers, declining therapy, and side effects. A total of 1914 SMS text interventions have been sent. Patients need an intervention $24 \%$ of the time and convert $48 \%(n=917)$ of the time. Additionally, $45 \%$ of conversions $(n=412)$ occurred within 1 hour of the intervention. Ninety percent $(n=44)$ of the patients responded directly to Nomi at least once. A total of 564 total responses have been received. Each patient has sent an average of 13 responses.

Conclusions: Patients had no perceived barriers to adopting Nomi. In fact, patients enjoy participating and interact frequently through responses. Personalized interventions, based on real-time data, quickly change patient behavior from what would have been a missed day, to a correct day. Metro Wellness integrated Nomi and medication adherence into the daily lives of their patients, through a direct communication channel. By using Nomi, Metro Wellness staff is able to connect with their patients more frequently, building stronger relationships, which has improved adherence in order to prevent HIV infection.

(iproc 2018;4(2):e11807) doi: $10.2196 / 11807$ 


\section{KEYWORDS}

behavior change; HIV/AIDS; interventions; medication adherence; real-time surveillance; tailored messaging; text messaging

Edited by T Hale; this is a non-peer-reviewed article. Submitted 02.08.18; accepted 29.08.18; published 17.09.18.

Please cite as:

Klimas C, Moreland C, Sleppy C, Nessen R, Mann M, De Jesus $R$

Improving Adherence to PrEP Though Real-Time Monitoring Paired with Personalized, Automated Text Interventions

iproc 2018;4(2):e11807

URL: http://www.iproc.org/2018/2/e11807/

doi: $\underline{10.2196 / 11807}$

PMID:

(C) Christian Klimas, Clyde Moreland, Cynthia Sleppy, Rebecca Nessen, Mark Mann, Rachel De Jesus. Originally published in Iproceedings (http://www.iproc.org), 17.09.2018. This is an open-access article distributed under the terms of the Creative Commons Attribution License (https://creativecommons.org/licenses/by/4.0/), which permits unrestricted use, distribution, and reproduction in any medium, provided the original work, first published in Iproceedings, is properly cited. The complete bibliographic information, a link to the original publication on http://www.iproc.org/, as well as this copyright and license information must be included. 